\title{
Trends and cyclical variation in the incidence of childhood type 1 diabetes in 26 European centres in the 25 year period 1989-2013: a multicentre prospective registration study
}

\author{
Christopher C. Patterson ${ }^{1}$ - Valma Harjutsalo ${ }^{2}$. Joachim Rosenbauer ${ }^{3}$ - Andreas $\mathrm{Neu}^{4}$ • Ondrej Cinek ${ }^{5}$. \\ Torild Skrivarhaug $^{6} \cdot$ Birgit Rami-Merhar $^{7} \cdot$ Gyula Soltesz $^{8} \cdot$ Jannet Svensson $^{9} \cdot$ Roger C. Parslow $^{10} \cdot$ Conxa Castell $^{11}$. \\ Eugen J. Schoenle ${ }^{12}$. Polly J. Bingley ${ }^{13}$. Gisela Dahlquist ${ }^{14}$. Przemysława K. Jarosz-Chobot ${ }^{15}$. \\ Dalè Marčiulionytè ${ }^{16,17}$. Edna F. Roche ${ }^{18}$. Ulrike Rothe ${ }^{19}$. Natasa Bratina ${ }^{20}$. Constantin lonescu-Tirgoviste ${ }^{21}$. \\ Ilse Weets ${ }^{22}$ - Mirjana Kocova ${ }^{23}$ • Valentino Cherubini ${ }^{24}$ • Natasa Rojnic Putarek ${ }^{25}$. Carine E. deBeaufort ${ }^{26}$. \\ Mira Samardzic ${ }^{27} \cdot$ Anders Green ${ }^{28}$
}

Received: 14 August 2018 / Accepted: 28 September 2018 / Published online: 28 November 2018

(C) The Author(s) 2018

\begin{abstract}
Aims/hypothesis Against a background of a near-universally increasing incidence of childhood type 1 diabetes, recent reports from some countries suggest a slowing in this increase. Occasional reports also describe cyclical variations in incidence, with periodicities of between 4 and 6 years.

Methods Age/sex-standardised incidence rates for the 0- to 14-year-old age group are reported for 26 European centres (representing 22 countries) that have registered newly diagnosed individuals in geographically defined regions for up to 25 years during the period 1989-2013. Poisson regression was used to estimate rates of increase and test for cyclical patterns. Joinpoint regression software was used to fit segmented log-linear relationships to incidence trends.

Results Significant increases in incidence were noted in all but two small centres, with a maximum rate of increase of $6.6 \%$ per annum in a Polish centre. Several centres in high-incidence countries showed reducing rates of increase in more recent years. Despite this, a pooled analysis across all centres revealed a 3.4\% (95\% CI 2.8\%, 3.9\%) per annum increase in incidence rate, although there was some suggestion of a reduced rate of increase in the 2004-2008 period. Rates of increase were similar in boys and girls in the 0 - to 4-year-old age group (3.7\% and 3.7\% per annum, respectively) and in the 5- to 9-year-old age group (3.4\% and $3.7 \%$ per annum, respectively), but were higher in boys than girls in the 10- to 14-year-old age group (3.3\% and $2.6 \%$ per annum, respectively). Significant 4 year periodicity was detected in four centres, with three centres showing that the most recent peak in fitted rates occurred in 2012.

Conclusions/interpretation Despite reductions in the rate of increase in some high-risk countries, the pooled estimate across centres continues to show a 3.4\% increase per annum in incidence rate, suggesting a doubling in incidence rate within approximately 20 years in Europe. Although four centres showed support for a cyclical pattern of incidence with a 4 year periodicity, no plausible explanation for this can be given.
\end{abstract}

Keywords Cyclical variation $\cdot$ Epidemiology $\cdot$ Incidence $\cdot$ Temporal change $\cdot$ Type 1 diabetes mellitus

Electronic supplementary material The online version of this article (https://doi.org/10.1007/s00125-018-4763-3) contains peer-reviewed but unedited supplementary material, which is available to authorised users.

Christopher C. Patterson

c.patterson@qub.ac.uk

Extended author information available on the last page of the article

\section{Introduction}

The increasing incidence of childhood type 1 diabetes has been well documented both in Europe, with an estimated annual increase of $3.9 \%$ (95\% CI 3.6\%, 4.2\%) during the period 1989-2003 [1], and worldwide, with an estimated annual increase of $2.8 \%$ (95\% CI 2.4\%, 3.2\%) in the period 1990-1999 [2]. Recent reports have, however, suggested a slowing or stabilisation in the rate of increase. 


\section{Research in context}

\section{What is already known about this subject?}

- Most countries in Europe have reported increasing incidence rates of type 1 diabetes in children

- In some countries with high incidence, rates have levelled off

- Studies have reported a cyclical variation in incidence with periodicities of between 4 and 6 years

What is the key question?

- Are the incidence rates of childhood type 1 diabetes in Europe continuing to increase?

What are the new findings?

- Based on the analysis of over 84,000 children registered in 22 European countries in a 25 year period from 1989 to 2013 , incidence rates are still increasing in all childhood age groups in most countries, with no clear signs of levelling off

- A significant 4 year cycle in incidence was observed in only four of 26 contributing centres

How might this impact on clinical practice in the foreseeable future?

- With slower progress in disease prevention than hoped for, the increasing number of children being diagnosed has important implications for those involved in the planning and delivery of healthcare, and in preventing and treating the complications of type 1 diabetes

In the USA, pooled data from five centres for children and adolescents under 20 years of age indicated a $1.8 \%(95 \% \mathrm{CI}$ $1.0 \%, 2.6 \%$ ) annual increase during 2002-2012 after adjustment for age, sex and race or ethnic group [3], and a similar rate of increase of $1.3 \%$ (95\% CI $0.0 \%, 2.5 \%$ ) has been reported for the Canadian province of British Columbia in the period 2002-2013 [4]. In Australia, a non-significant annual increase of $0.4 \%$ (95\% CI $-0.1 \%, 0.9 \%)$ was reported in the under-15-year-old population during the period 2000-2011, although a significant increase of $1.2 \%$ (95\% CI $0.4 \%$, $2.1 \%$ ) was observed in the 10- to 14-year-old age group [5]. Within Europe, no increase was found in Sweden during the period 2005-2007 despite a prolonged period of uniform increase during the previous 15 years [6]. Very similar levelling incidence rates, beginning at about the same time and with longer periods of observation, were subsequently reported in two other high-incidence Scandinavian countries, Finland [7] and Norway [8]. In contrast, a report from Zhejiang province in the low-incidence region of China described a very rapid $12.0 \%$ $(95 \%$ CI $7.6 \%, 16.6 \%)$ increase in annual incidence rate among those aged under 20 years during the period 2007-2013 [9].

There have also been reports in the literature of a cyclical variation in year-to-year incidence rates. The earliest report was from the Yorkshire regional registry in England during the period 1978-1990, which described a marked epidemic pattern with peaks at 4 year intervals [10]. A subsequent brief report from a neighbouring area of north-east England in the period 1990-2007 described a 6 year cyclical pattern with an amplitude of $\pm 25 \%$ [11], but there is no established register in the region and no support for the claim of high ascertainment.
A sinusoidal cyclical pattern with peaks observed every 5 years and an amplitude of $\pm 14 \%$ has also been reported from Western Australia for the period 1985-2010 [12], and was subsequently replicated in an Australia-wide analysis during the period 2000-2011 [5]. A report from five regions of Poland during the period 1989-2012 using Fourier series methods found a 5.33 year periodicity in rates, with an amplitude of $\pm 8 \%$ [13].

To help clarify the recent trends in European incidence rates, an analysis of EURODIAB registry data from over 84,000 children in 26 European centres representing 22 countries is presented for the 25 year period 1989-2013, with separate estimates of incidence rate increases derived in each of five subperiods. This dataset also provides an excellent opportunity to investigate the claims of cyclical variation in incidence rates.

\section{Methods}

The establishment of the registries and case definition used has previously been described [14]. Type 1 diabetes was defined on the basis of a clinical diagnosis made by a physician, omitting cases that were secondary to other conditions (e.g. cystic fibrosis or high-dose corticosteroid treatment). Registries attempt to capture prospectively all newly diagnosed individuals in a geographically defined region. Primary and secondary sources of ascertainment were recorded for each child, and these were used to estimate completeness by capture-recapture methodology. The completeness 
findings for 1989-2008 have previously been reported as being considerably in excess of $90 \%$ in most of the registries (as reported by ESM Table 2 from the 20 year report) [15]. The geographical coverage of the 26 registries is shown in Fig. 1 and represents $23 \%$ of the estimated European childhood population in 2011 (excluding Belarus, Ukraine and the Russian Federation). Ethics approval was obtained by individual centres where required.

Incidence rates were obtained by dividing the numbers of registered children by annual population estimates. Standardisation of rates was obtained by the direct method with a standard population comprising equal numbers in each of six subgroups defined by age group ( $0-4$ years, 5-9 years and 10-14 years) and sex. Standard errors for the directly standardised rates were also calculated [16]. Trends in annual incidence rates in each country were investigated in the 25 year period using Poisson regression incorporating an adjustment for age group and sex. Comparisons of trends between age groups and sexes were obtained within each country by incorporating interactions into the Poisson regression model. The Joinpoint regression analysis program version 4.2 (Statistical Methodology and Applications Branch and Data Modeling Branch, National Cancer Institute, Bethesda, MD, USA) was used to fit segmented regression lines to the logarithmically transformed directly standardised incidence rates, taking account of their standard errors. Pooled estimates of rates of increase across all 26 centres were obtained using a mixed effects Poisson regression model with centre treated as a random effect and age and sex as fixed effects.

Motivated by reports in the literature of 4, 5 and 6 year cycles in incidence rate, sine and cosine terms representing such cycles were added to Poisson regression models for annual age-/sex-specific incidence rates, along with terms for age group and sex as well as the segmented log-linear trends with year as identified by the Joinpoint analysis. The sine and cosine terms are similar to those described for the study of seasonal variation in month-to-month counts [17] but were adapted for the detection of cyclical variation in yearly rates.

Statistical analyses were performed in SPSS version 24 (IBM Corp, Armonk, NY, USA) and Stata release 14 (StataCorp, College Station, TX, USA). Unless otherwise stated, hypothesis testing was performed at the $5 \%$ significance level $(p<0.05)$.

\section{Results}

Ascertainment rates remained in excess of $90 \%$ for most centres, although data were not available for all of these (see electronic supplementary material [ESM] Table 1). Table 1 shows the total numbers of children registered during the 25 year period 1989-2013 in each of the 26 centres, and the age- and sex-standardised incidence rates (with standard errors) in the 5 year subperiods 1989-1993, 1994-1998, 1999-

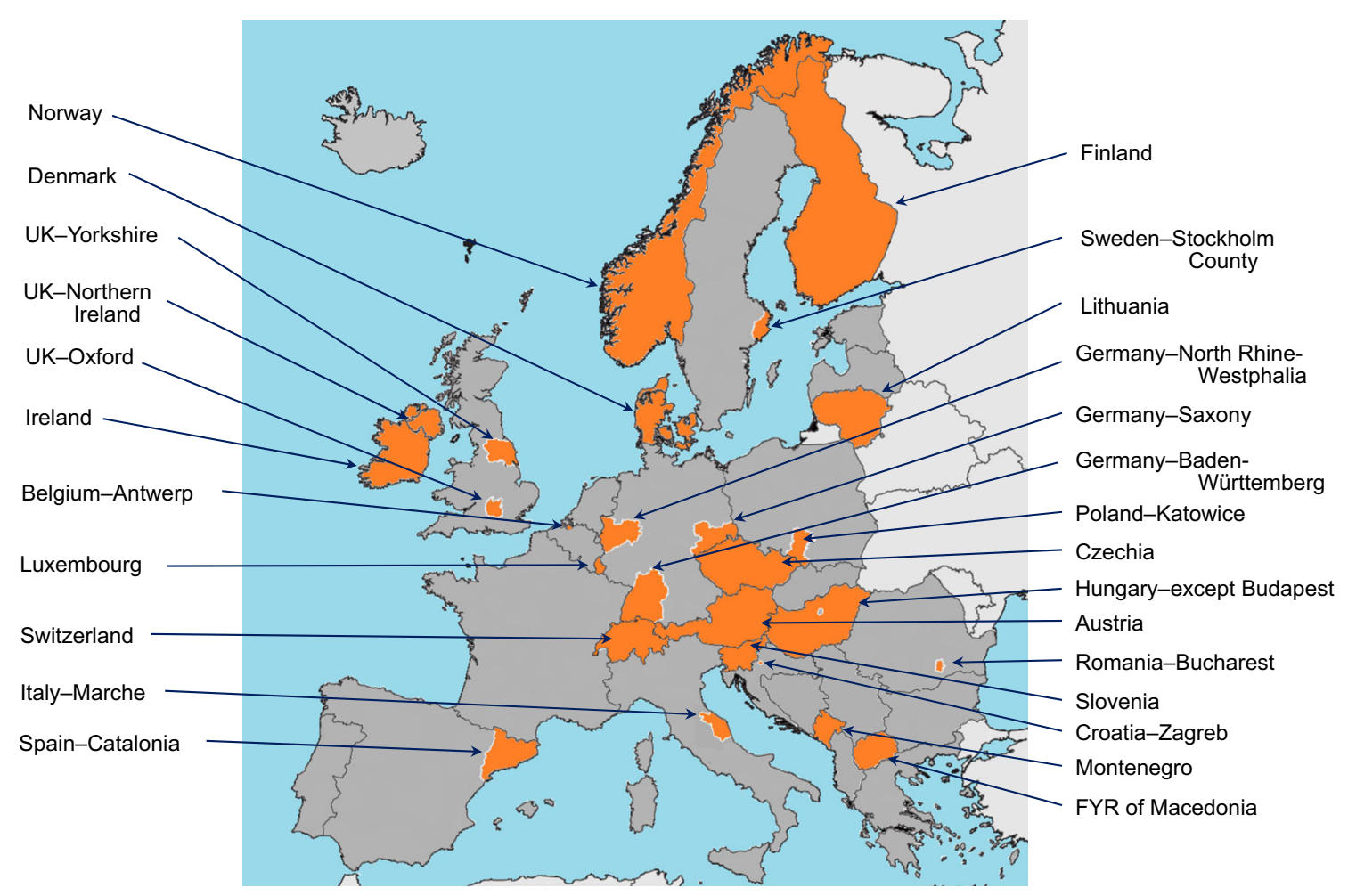

Fig. 1 Map of 26 participating EURODIAB centres (whole nations unless a region is specified). Administrative boundaries: (OEuroGeographics 2018; adapted with permission. FYR, Former Yugoslav Republic 
Table 1 Incidence rates per 100,000 person-years (with standard errors) standardised for age group and sex in 5 year periods for 26 EURODIAB centres

\begin{tabular}{|c|c|c|c|c|c|c|c|c|c|c|c|c|}
\hline \multirow[t]{3}{*}{ Centre } & \multirow{3}{*}{ Years } & \multirow{3}{*}{ Cases } & \multicolumn{10}{|c|}{ Period } \\
\hline & & & \multicolumn{2}{|c|}{ 1989-1993 } & \multicolumn{2}{|c|}{ 1994-1998 } & \multicolumn{2}{|c|}{ 1999-2003 } & \multicolumn{2}{|c|}{ 2004-2008 } & \multicolumn{2}{|c|}{ 2009-2013 } \\
\hline & & & Rate & $\mathrm{SE}$ & Rate & $\mathrm{SE}$ & Rate & SE & Rate & SE & Rate & $\mathrm{SE}$ \\
\hline Austria-whole nation & 1989-2013 & 4594 & 9.0 & 0.4 & 9.8 & 0.4 & 13.2 & 0.4 & 17.3 & 0.5 & 19.7 & 0.6 \\
\hline Belgium-Antwerp & 1989-2013 & 610 & 10.9 & 1.2 & 13.0 & 1.3 & 16.4 & 1.4 & 16.3 & 1.4 & 18.1 & 1.5 \\
\hline Croatia-Zagreb & 1995-2013 & 364 & - & & 11.1 & 1.5 & 14.8 & 1.6 & 19.4 & 1.8 & 18.8 & 1.8 \\
\hline Czechia-whole nation & 1989-2013 & 6528 & 8.5 & 0.3 & 11.5 & 0.4 & 17.1 & 0.5 & 19.3 & 0.5 & 21.8 & 0.5 \\
\hline Denmark-whole nation $^{\mathrm{a}}$ & 1989-2013 & 4148 & 17.0 & 1.2 & 16.3 & 1.2 & 22.5 & 0.7 & 25.2 & 0.7 & 27.0 & 0.7 \\
\hline Finland-whole nation & 1989-2011 & 11,132 & 38.2 & 0.9 & 46.7 & 1.0 & 54.5 & 1.1 & 63.3 & 1.2 & 60.9 & 1.5 \\
\hline Germany-Baden-Württemberg & 1989-2013 & 6931 & 11.0 & 0.4 & 13.0 & 0.4 & 15.4 & 0.4 & 22.0 & 0.5 & 23.1 & 0.6 \\
\hline Germany-North Rhine-Westphalia $^{\mathrm{b}}$ & 1989-2013 & 10,202 & 13.3 & 0.8 & 16.2 & 0.9 & 20.9 & 0.4 & 24.0 & 0.4 & 26.9 & 0.5 \\
\hline Germany-Saxony & 1998-2013 & 1463 & - & & 11.6 & 1.5 & 15.6 & 0.8 & 20.1 & 1.0 & 22.8 & 1.0 \\
\hline Hungary-except Budapest & 1989-2013 & 4283 & 9.0 & 0.3 & 10.7 & 0.4 & 12.4 & 0.4 & 18.3 & 0.6 & 20.0 & 0.6 \\
\hline Ireland-whole nation & 2008-2013 & 1566 & - & & - & & - & & 27.5 & 1.7 & 27.5 & 0.8 \\
\hline Italy-Marche & 1989-2013 & 579 & 9.6 & 1.0 & 11.9 & 1.1 & 12.6 & 1.2 & 12.6 & 1.1 & 11.6 & 1.1 \\
\hline Lithuania-whole nation & 1989-2013 & 1862 & 7.3 & 0.4 & 8.2 & 0.5 & 10.3 & 0.6 & 14.2 & 0.7 & 19.9 & 0.9 \\
\hline Luxembourg-whole nation & 1989-2013 & 312 & 11.4 & 1.9 & 12.3 & 1.8 & 15.7 & 2.0 & 18.4 & 2.1 & 18.6 & 2.0 \\
\hline Macedonia (FYR)-whole nation & 1989-2013 & 584 & 3.2 & 0.4 & 3.9 & 0.4 & 6.0 & 0.5 & 7.2 & 0.6 & 7.7 & 0.7 \\
\hline Montenegro-whole nation & 1996-2013 & 362 & - & & 10.1 & 1.5 & 14.7 & 1.5 & 17.4 & 1.7 & 18.5 & 1.8 \\
\hline Norway-whole nation & 1989-2013 & 6348 & 22.7 & 0.8 & 24.6 & 0.8 & 29.6 & 0.8 & 33.1 & 0.9 & 33.6 & 0.9 \\
\hline Poland-Katowice & 1989-2013 & 2360 & 5.2 & 0.3 & 7.9 & 0.4 & 13.0 & 0.6 & 16.5 & 0.7 & 20.1 & 0.8 \\
\hline Romania-Bucharest & 1989-2013 & 714 & 4.7 & 0.5 & 5.6 & 0.5 & 9.7 & 0.8 & 12.3 & 1.0 & 13.4 & 1.0 \\
\hline Slovenia-whole nation & 1989-2013 & 949 & 7.8 & 0.6 & 9.1 & 0.7 & 11.1 & 0.8 & 14.9 & 1.0 & 16.3 & 1.1 \\
\hline Spain-Catalonia & 1989-2013 & 3447 & 12.4 & 0.5 & 13.6 & 0.5 & 13.1 & 0.5 & 12.1 & 0.5 & 16.1 & 0.5 \\
\hline Sweden-Stockholm County & 1989-2013 & 2704 & 25.8 & 1.3 & 25.6 & 1.3 & 34.5 & 1.4 & 35.1 & 1.4 & 39.6 & 1.5 \\
\hline Switzerland-whole nation & 1991-2013 & 3020 & 7.9 & 0.5 & 8.3 & 0.4 & 11.0 & 0.4 & 13.1 & 0.5 & 13.4 & 0.5 \\
\hline UK-Northern Ireland & 1989-2013 & 2652 & 20.0 & 1.0 & 24.7 & 1.1 & 29.9 & 1.3 & 34.2 & 1.4 & 34.4 & 1.4 \\
\hline UK-Oxford & 1989-2013 & 2920 & 17.2 & 0.8 & 21.7 & 0.9 & 24.0 & 1.0 & 25.2 & 1.0 & 22.8 & 0.9 \\
\hline UK-Yorkshire & 1989-2011 & 3660 & 16.1 & 0.7 & 19.7 & 0.7 & 23.5 & 0.8 & 25.5 & 0.9 & 31.0 & 1.2 \\
\hline
\end{tabular}

${ }^{a}$ Four counties only for $1989-1998$

${ }^{\mathrm{b}}$ Düsseldorf region only for 1989-1998

FYR, Former Yugoslav Republic

2003, 2004-2008 and 2009-2013. The age- and sex-specific incidence rates for each period used in the calculations are shown in ESM Table 2.

As illustrated in Fig. 2, the trends in age-standardised rates differed little between the sexes. Two of the centres (Denmark and Germany-North Rhine-Westphalia) expanded their geographical coverage in 1999, and the lines for these centres are therefore shown with a break at that point, although in both cases the degree of any discontinuity appears to be minimal. In a preliminary analysis, incidence rate increases were estimated using Poisson regression analysis assuming a constant rate of increase throughout the period.

Figure 3 shows that the rate of increase was highest in the Poland-Katowice centre (6.6\% per annum) and the lowest in the
Spain-Catalonia centre $(0.5 \%$ per annum). Except for the Ireland and Italy-Marche centres, all rates of increase were significantly greater than zero. A significant inverse relationship was found between the rate of increase in each centre and its directly standardised rate during the entire period (Spearman's rank correlation coefficient, $r_{\mathrm{s}}=-0.45, p=0.02$ ), indicating that the percentage increase in rate tended to be lower in centres with higher rates. A comparison of rates of increase between the sexes within each centre revealed differences in three centres, each showing a significantly higher rate of increase in boys than girls. A comparison of rates of increase between age groups within each centre revealed differences in nine centres, and in six of the nine the highest rate of increase was found in the 0 - to 4-year-old age group. Full details are available in ESM Table 3. 


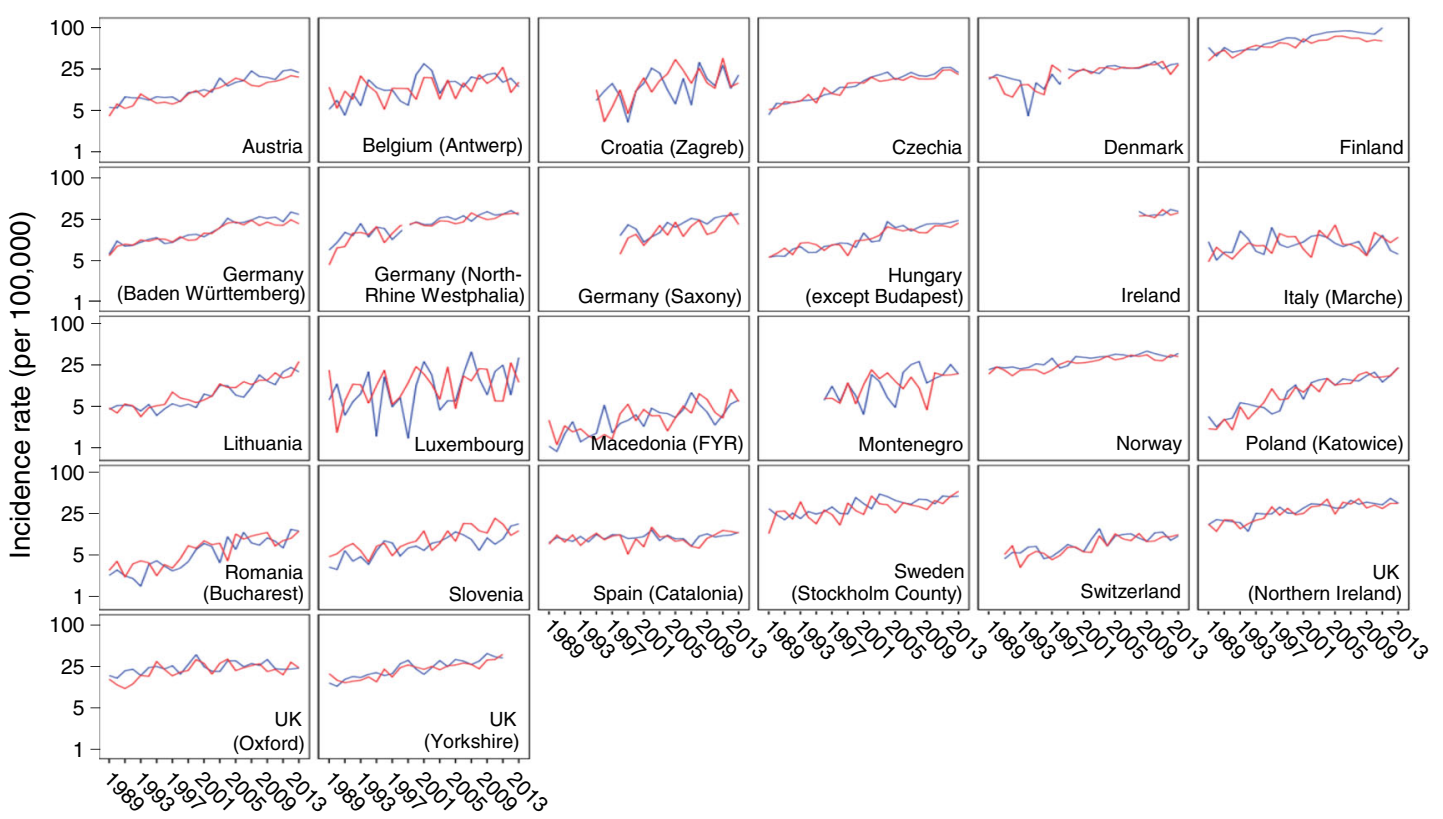

Fig. 2 Trends in age-standardised incidence rates, plotted on a logarithmic scale, by sex for type 1 diabetes in 26 European centres during 1989 2013. Blue lines, boys; red lines, girls. Breaks are shown for Denmark and Germany (North Rhine-Westphalia) between 1998 and 1999 because

Mixed effects Poisson regression provided estimated rates of increase in the pooled data from the 26 centres, as shown in Table 2. Overall, the annual rate of increase was estimated to be $3.4 \%$ (95\% CI $2.8 \%, 3.9 \%)$. Rates of increase were similar in boys and girls in the 0 - to 4-year-old age group (3.7\% and $3.7 \%$ per annum, respectively) and in the 5- to 9-year-old age of increased coverage of these registers, but any discontinuities appear to be very minor. Macedonia (FYR), Former Yugoslav Republic of Macedonia

group (3.4\% and $3.7 \%$ per annum, respectively), but were higher in boys than girls in the 10- to 14-year-old age group (3.3\% and 2.6\% per annum, respectively). The estimates of overall rate of increase by period suggested a slowing in 2004-2008, but the rate of increase appeared to have almost returned to previous levels in the 2009-2013 period.
Fig. 3 Estimated rates of annual increase in type 1 diabetes in 26 European centres. Rates of increase in individual centres were derived from Poisson regression analyses with adjustment for age, sex, age $\times$ sex interaction and inclusion of a $\log$ linear term for year in the model. The overall pooled estimate was derived from a Poisson regression with centre as a random effect. FYR, Former Yugoslav Republic; N., North

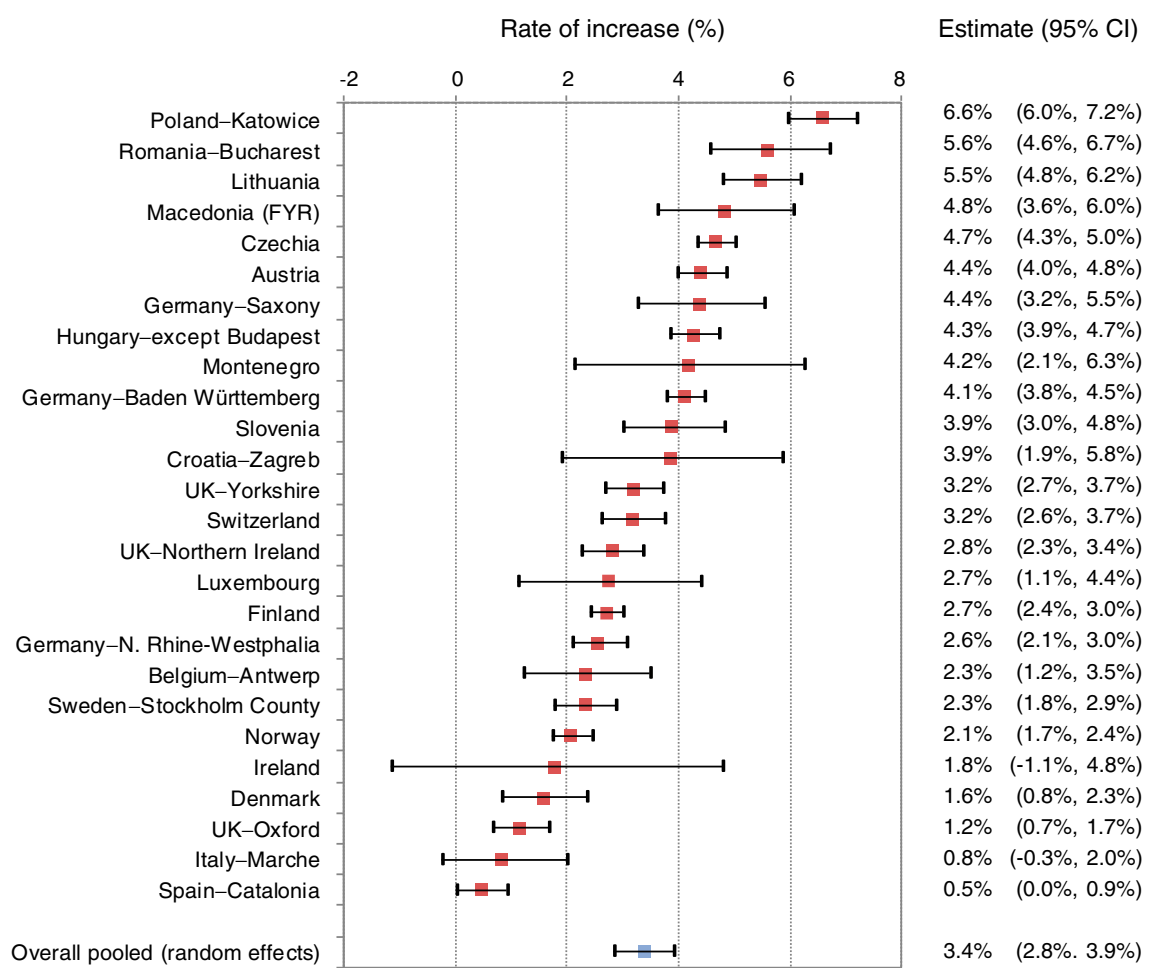


Table 2 Annual increases in incidence rate over a 25 year period pooled over centres as estimated by mixed effects Poisson regression in subgroups defined by age group, sex and time period

\begin{tabular}{lcc}
\hline Subgroup & Annual increase $(\%)$ & $(95 \%$ CI $)$ \\
\hline Boys & & \\
0-4 years old & 3.7 & $(3.0,4.4)$ \\
5-9 years old & 3.4 & $(2.7,4.0)$ \\
10-14 years old & 3.3 & $(2.8,3.8)$ \\
0-14 years old & 3.5 & $(2.9,4.0)$ \\
Girls & & \\
0-4 years old & 3.7 & $(2.9,4.5)$ \\
5-9 years old & 3.7 & $(3.2,4.2)$ \\
$10-14$ years old & 2.6 & $(2.2,3.0)$ \\
$0-14$ years old & 3.3 & $(2.8,3.8)$ \\
Period & & \\
$1989-1993$ & 4.1 & $(2.7,5.6)$ \\
$1994-1998$ & 3.2 & $(1.9,4.5)$ \\
$1999-2003$ & 4.1 & $(0.2,2.1)$ \\
$2004-2008$ & 1.1 & $(1.7,3.7)$ \\
$2009-2013$ & 2.7 & $(2.8,3.9)$ \\
$1989-2013^{\text {a }}$ & 3.4 &
\end{tabular}

${ }^{\mathrm{a}}$ Overall time period

The fitted Joinpoint segmented regression analyses for each centre are presented in ESM Fig. 1. The best fit for 18 of the 26 centres throughout the period was a log-linear increase in the agestandardised rate. Six centres showed more rapid increases in an early period followed by lower rates of increase in a later period. In two Central European centres (Czechia and Poland-
Katowice), the change took place in 2002, at roughly the same time as in two UK centres (UK-Oxford in 2000 and UKNorthern Ireland in 2003). In two Scandinavian centres (Finland and Norway), the levelling off took place a little later, in the years 2005 and 2007, respectively. Only in a single centre (Lithuania) was an initially low rate of increase followed by a period after 1996 with a higher rate of increase. The final centre (Germany-Baden-Württemberg) showed a more complex pattern, with steady rates of increase in the early and late part of the 25 year period separated by a short period of more rapid increase in 2001-2004.

Poisson regression results provided most support for a 4 year periodicity, with four centres giving likelihood ratio tests that attained significance at the reduced $p<0.01$ level (to allow for multiple testing) compared with none for a 5 year periodicity and two for a 6 year periodicity (tests of significance summarised in ESM Table 4). Plots of the observed age-standardised annual incidence rates and the fitted rates for 4 year cycles are shown in Fig. 4 for these four centres. One of the four centres showed its most recent peak in fitted incidence rate in 2011 (Switzerland, with an amplitude of $\pm 10 \%$ superimposed on the log-linear increasing trend), while the three remaining centres showed the most recent peaks in 2012 (Germany-North Rhine-Westphalia with an amplitude of $\pm 5 \%$, Germany-Saxony with an amplitude of $\pm 15 \%$ and UK-Oxford with an amplitude of $\pm 9 \%$ ).

\section{Discussion}

Our analyses of individual centre results confirmed the recent slowing of incidence rate increases in some high-incidence
Fig. 4 Observed (continuous blue line) and fitted (red dashed line) standardised incidence rates (per 100,000 person-years) obtained by Poisson regression in four centres that showed significant $(p<0.01) 4$ year periodicity when superimposed on long-term Joinpoint segmented regression trends: (a) Germany-North Rhine-Westphalia;

(b) Germany-Saxony; (c) Switzerland; (d) UK-Oxford
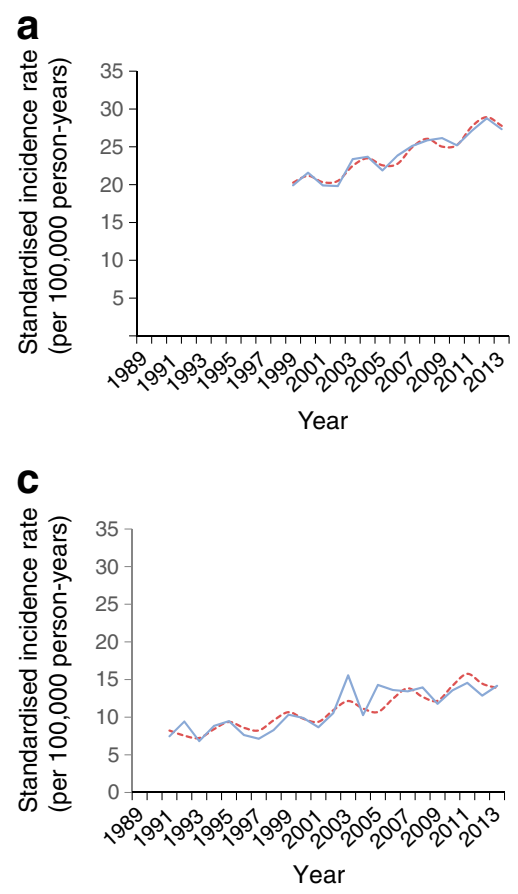

b

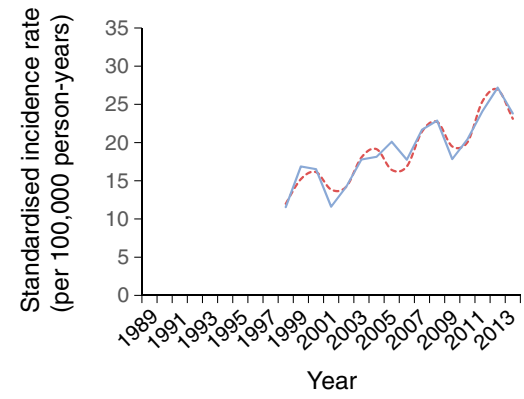

d

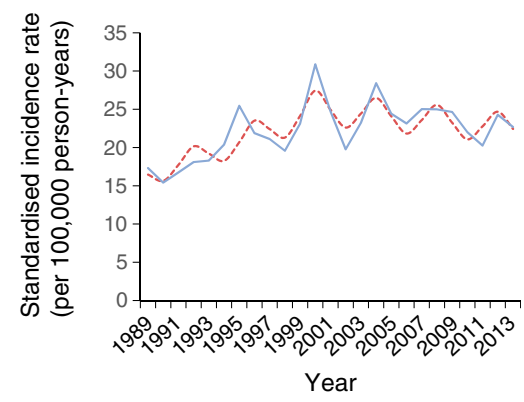


areas such as Finland [7] and Norway [8], but using only data from Stockholm County we were unable to detect the same pattern that had previously been reported from Sweden [6]. Two of the three centres from the UK, another country with high rates, also showed reducing rates of increase, although these seemed to have begun a few years earlier than in Scandinavia.

Our pooled estimates suggest that, despite some high-risk countries showing some slowing in the rate of increase in recent years, the overall pattern is still one of an approximately $3 \%$ per annum increase, although with a possible temporary slowing in the 2004-2008 period. As previously noted in our 15 year analysis, the rate of increase in girls aged 10-14 years is less marked than in other age/sex subgroups [1].

Our analysis shows that, in the majority of centres, a steady log-linear increase in rates with time provided a good description of the temporal changes, with only a few (mainly highincidence) areas showing some evidence of non-uniformity. The cyclical pattern in incidence observed in four of our 26 centres is consistent with the earliest report of a 4 year cyclical incidence pattern [10], but subsequent reports have described 5 year or 6 year periodicities [11-13], for which we found little support in our data.

No clear rationale for periodicity has yet been proposed and, to the authors' knowledge, no climatological factor [18], viral infection [19] or other environmental exposure has yet been firmly established that exhibits such a cyclical pattern. Since autoimmunity and progressive beta cell destruction typically start long before the clinical diagnosis of type 1 diabetes, the periodicity in diagnosis could be indicative of cycles of infectious disease that accelerate the diagnosis rather than initiate the disease. Regular cycles of infectious diseases are well known from classic work done before populationwide vaccination for measles, an extremely contagious viral disease of childhood; this research showed that, in an otherwise stable population, epidemic cyclicity depends on community size [20].

It is also unclear why only a small proportion of the 26 centres showed this periodicity and, although we acknowledge that power may be limited in smaller centres, it was not apparent in many of the largest centres that might be expected to have had a high power to detect it. This could perhaps suggest that it may have more localised origins. What determines this localisation remains enigmatic, as cyclical patterns were absent in Austria, Czechia and Germany-BadenWürttemberg, three large registers each with neighbouring areas where pronounced cyclical patterns were noted. It is possible that not only the size of the population, but also its spatial structure (i.e. the size of the communities, and their mutual links) may play an important role in the ability of the hypothetical infectious accelerator to be transmitted [21].

To our knowledge, among autoimmune conditions, only incidence cycles in juvenile idiopathic arthritis have been correlated to cycles of serologically confirmed microbial agents - in a Canadian study, peak incidences of arthritis were concurrent with peaks of Mycoplasma pneumoniae, whereas no such phenomenon was noted for the incidence of seronegative (i.e. non-immune mediated) spondyloarthropathies [22]. The recent report of a twofold risk of type 1 diabetes diagnosed by the age of 30 years among those with laboratory-confirmed pandemic influenza A (H1N1) [23] may stimulate interest in less consistent patterns of incidence peaks in type 1 diabetes since localised seasonal influenza epidemics (as opposed to much rarer pandemics) can occur at irregular intervals [24].

Most of the participating registers have maintained their completeness of coverage at levels in excess of $90 \%$ in the most recent 5 year period, but these estimates of completeness rely on an assumption of independence in the primary and secondary sources that is very difficult to verify. As more sophisticated information systems for drug prescribing and clinical management become available, it seems likely that the traditional approach based on notification of individual new diagnoses will give way to more automated approaches that take advantage of these information systems.

Although it could be argued that the diagnosis of type 1 diabetes should ideally be confirmed by the presence of one or more specific autoimmune markers [25], this is seldom done in clinical practice, and we have therefore continued to use a pragmatic definition of type 1 diabetes based on clinical judgement. A UK study found that all but 8 (3\%) of 256 clinically diagnosed cases of type 1 diabetes in individuals aged 20 years or younger were positive for one or more of four antibodies [26], but the case for routine antibody testing at diagnosis is not compelling [27]. Individuals diagnosed before 6 months of age now tend to be routinely investigated for monogenic forms of the disease [28], but the number of such cases is very small. Findings in the literature on whether or not type 2 diabetes is becoming more common in children and adolescents are inconsistent [29-31], but the distinction between the two types of diabetes is generally not difficult in the paediatric age group. Furthermore, European studies [30-33] confirm that the rate of type 2 diabetes is a small fraction of that of type 1 diabetes, and we do not therefore feel that misclassification of type 2 diabetes represents a serious challenge to the validity of our findings.

The use of mixed effects Poisson regression, in which age group and sex are considered as fixed effects but centre is treated as a random effect, gives similar estimates of the increase in incidence rate to the more conventional fixed effects analysis that we have used in previous analyses; however, confidence limits for the mixed effects model tend to be rather wider and should give a fairer reflection of uncertainty in the estimates of incidence rate increase. Taking into account the uncertainty associated with our overall incidence rate increase of $3.4 \%$ (95\% CI 2.8\%, 3.9\%), we may expect to see a doubling in European incidence in between 18 and 25 years if the trends evident in the last 25 years are maintained. 
The steadily increasing number of children being diagnosed with this chronic disease, which is associated with well-documented, life-long increases in morbidity and mortality, has important implications for those planning and delivering healthcare. The limited success in identifying either environmental causes or gene-environment interactions that could eventually lead to disease prevention means that efforts must continue to improve quality of care to help reduce long-term complications and diabetes-related deaths. Key to this is the improvement in glycaemic control that will be achieved not only by more sophisticated methods of insulin delivery, but also by an increased investment in services to support welltrained and dedicated care teams in sufficient numbers to meet the growing needs of this group of children and their families.

The EURODIAB childhood type 1 diabetes registers, with their wide, population-based coverage of European regions of differing incidence, and their high levels of case ascertainment, will continue to provide a valuable source of data for monitoring the future incidence of childhood type 1 diabetes.

Acknowledgements The authors acknowledge the Austrian Diabetes Incidence Study Group, the Belgian Diabetes Registry, the Czech Childhood Diabetes Register and the Czech Association of Parents and Friends of Diabetic Children, the Danish Study Group of Diabetes in Childhood and contributors to DanDiabKids, the Chronic Disease Prevention Unit of the Finnish National Institute for Health and Welfare, the Baden-Württemberg Diabetes Incidence Registry (DIARY), the German Paediatric Surveillance Unit, DPV Science Initiative, Ulm University, the German Competence Network Diabetes Mellitus and the German Center for Diabetes Research (DZD), the Saxonian Childhood Diabetes Register Group, the Hungarian Childhood Diabetes Epidemiology Group, the Irish Childhood Diabetes National Register, the Registry for Incidence of Diabetes in Italy (RIDI), the Lithuanian Childhood Diabetes Registry Study Group, the Norwegian Childhood Diabetes Study Group, the Catalan Epidemiology Type 1 Diabetes Study Group, the Swedish Childhood Diabetes Study Group, the Managed Clinical Network for Paediatric Diabetes in Northern Ireland, the Bart's-Oxford Study Group and the Yorkshire Register of Diabetes in Children and Young People.

Data availability Much of the data generated or analysed during this study are included in this article and its accompanying electronic supplementary material (ESM) files. Requests for further data should be sent to the corresponding author.

Funding The following centres received support as listed: Austria centre from Sanofi and Novo-Nordisk, Czechia centre from the Czech Ministry of Health (grant 00064203), Germany-North Rhine-Westphalia centre from the German Federal Ministry of Education and Research, Ireland centre from the National Children's Hospital Foundation, Norway centre from the South-Eastern Norway Regional Health Authority, Poland-Katowice centre from the Medical University of Silesia (grants SUM KNW-1-083/K/ 6/K and SUM KNW-1-063/N/7/K, Sweden-Stockholm centre from the Swedish Research Council (project number 07531), UK-Oxford centre from Diabetes UK, UK-Yorkshire centre from the UK Department of Health and the Yorkshire and Humber Children and Young People's Diabetes Network. IW was in receipt of a fellowship from the Belgian Fund for Scientific Research. Funding to establish the collaboration was supplied by European Community Concerted Action Program grants (BMH1-CT92-0043, BMH4-CT96-0577 and IC20-CT96-0070).
Duality of interest The authors declare that there is no duality of interest associated with this manuscript.

Contribution statement AG set up the collaboration and coordinated the group until 1998 and together with GD established the registration methodology. GS coordinated the group from 1998 to 2009. CCP has coordinated the group since 2010, undertook the statistical analysis and wrote a first draft of the report. JR also contributed to the statistical analysis. The remaining authors established and/or maintained the registration process in the different centres and validated the ascertainment level. All authors commented on a draft of the report and approved the final manuscript. CCP is the guarantor of this work.

Open Access This article is distributed under the terms of the Creative Commons Attribution 4.0 International License (http:// creativecommons.org/licenses/by/4.0/), which permits unrestricted use, distribution, and reproduction in any medium, provided you give appropriate credit to the original author(s) and the source, provide a link to the Creative Commons license, and indicate if changes were made.

\section{References}

1. Patterson CC, Dahlquist GG, Gyürüs E et al (2009) Incidence trends for childhood type 1 diabetes in Europe during 1989-2003 and predicted new cases 2005-20: a multicentre prospective registration study. Lancet 373(9680):2027-2033. https://doi.org/10.1016/ S0140-6736(09)60568-7

2. DIAMOND Project Group (2006) Incidence and trends of childhood type 1 diabetes worldwide 1990-1999. Diabet Med 23(8): 857-866. https://doi.org/10.1111/j.1464-5491.2006.01925.x

3. Mayer-Davis EJ, Lawrence JM, Dabelea D et al (2017) Incidence trends of type 1 and type 2 diabetes among youths, 2002-2012. N Engl J Med 376(15):1419-1429. https://doi.org/ 10.1056/NEJMoa1610187

4. Fox DA, Islam N, Sutherland J, Reimer K, Amed S (2018) Type 1 diabetes incidence and prevalence trends in a cohort of Canadian children and youth. Pediatr Diabetes 19(3):501-505. https://doi. org/10.1111/pedi. 12566

5. Haynes A, Bulsara MK, Bower C, Jones TW, Davis EA (2015) Regular peaks and troughs in the Australian incidence of childhood type 1 diabetes mellitus (2000-2011). Diabetologia 58(11):25132516. https://doi.org/10.1007/s00125-015-3709-2

6. Berhan Y, Waernbaum I, Lind T, Möllsten A, Dahlquist G, the Swedish Childhood Diabetes Study Group (2011) Thirty years of prospective nationwide incidence of childhood type 1 diabetes: the accelerating increase by time tends to level off in Sweden. Diabetes 60(2):577-581. https://doi.org/10.2337/db10-0813

7. Harjutsalo V, Sund R, Knip M, Groop PH (2013) Incidence of type 1 diabetes in Finland. JAMA 310(4):427-428. https://doi.org/10. 1001/jama.2013.8399

8. Skrivarhaug T, Stene LC, Drivvoll AK, Strøm H, Joner G, Norwegian Childhood Diabetes Study Group (2014) Incidence of type 1 diabetes in Norway among children aged $0-14$ years between 1989 and 2012: has the incidence stopped rising? Results from the Norwegian Childhood Diabetes Registry. Diabetologia 57(1):5762. https://doi.org/10.1007/s00125-013-3090-y

9. Wu HB, Zhong JM, Hu RY et al (2016) Rapidly rising incidence of type 1 diabetes in children and adolescents aged 0-19 years in Zhejiang, China, 2007 to 2013. Diabet Med 33(10):1339-1346. https://doi.org/10.1111/dme.13010

10. Staines A, Bodansky HJ, Lilley HE, Stephenson C, McNally RJ, Cartwright RA (1993) The epidemiology of diabetes mellitus in the United Kingdom: the Yorkshire Regional Childhood Diabetes 
Register. Diabetologia 36(12):1282-1287. https://doi.org/10.1007/ BF00400806

11. McNally RJ, Court S, James PW et al (2010) Cyclical variation in type 1 childhood diabetes. Epidemiology 21(6):914-915. https:// doi.org/10.1097/EDE.0b013e3181f38f3f

12. Haynes A, Bulsara MK, Bower C, Jones TW, Davis EA (2012) Cyclical variation in the incidence of childhood type 1 diabetes in Western Australia (1985-2010). Diabetes Care 35(11):2300-2302. https://doi.org/10.2337/dc12-0205

13. Chobot A, Polanska J, Brandt A et al (2017) Updated 24-year trend of type 1 diabetes incidence in children in Poland reveals a sinusoidal pattern and sustained increase. Diabet Med 34(9):1252-1258. https://doi.org/10.1111/dme.13345

14. Green A, Gale EA, Patterson CC (1992) Incidence of childhoodonset insulin-dependent diabetes mellitus: the EURODIAB ACE study. Lancet 339(8798):905-909. https://doi.org/10.1016/01406736(92)90938-Y

15. Patterson CC, Gyürüs E, Rosenbauer J et al (2012) Trends in childhood type 1 diabetes incidence in Europe during 1989-2008: evidence of non-uniformity over time in rates of increase. Diabetologia 55(8):2142-2147. https://doi.org/10.1007/s00125-012-2571-8

16. Morris JA, Gardner MJ (1988) Calculating confidence intervals for relative risks (odds ratios) and standardised ratios and rates. Br Med J (Clin Res Ed) 296(6632):1313-1316. https://doi.org/10.1136/ bmj.296.6632.1313

17. Stolwijk AM, Straatman H, Zielhuis GA (1999) Studying seasonality using sine and cosine functions in regression analysis. $\mathrm{J}$ Epidemiol Community Health 53(4):235-238. https://doi.org/10. 1136/jech.53.4.235

18. Patterson CC, Gyürüs E, Rosenbauer J et al (2015) Seasonal variation in month of diagnosis in children with type 1 diabetes registered in 23 European centers during 1989-2008: little short-term influence of sunshine hours or average temperature. Pediatr Diabetes 16(8):573-580. https://doi.org/10.1111/pedi.12227

19. Craig ME, Nair S, Stein H, Rawlinson WD (2013) Viruses and type 1 diabetes: a new look at an old story. Pediatr Diabetes 14(3):149_ 158. https://doi.org/10.1111/pedi.12033

20. Bartlett MS (1957) Measles periodicity and community size. J R Stat Soc Ser A 120(1):48-70. https://doi.org/10.2307/2342553

21. Sun GQ, Jusup M, Jin Z, Wang Y, Wang Z (2016) Pattern transitions in spatial epidemics: mechanisms and emergent properties. Phys Life Rev 19:43-73. https://doi.org/10.1016/j.plrev.2016.08.002

22. Oen K, Fast M, Postl B (1995) Epidemiology of juvenile rheumatoid arthritis in Manitoba, Canada, 1975-92: cycles in incidence. J Rheumatol 22(4):745-750
23. Ruiz PLD, Tapia G, Bakken IJ et al (2018) Pandemic influenza and subsequent risk of type 1 diabetes: a nationwide cohort study. Diabetologia 61(9):1996-2004. https://doi.org/10.1007/s00125018-4662-7

24. Chowell G, Miller MA, Viboud C (2008) Seasonal influenza in the United States, France, and Australia: transmission and prospects for control. Epidemiol Infect 136(6):852-864. https://doi.org/10.1017/ S0950268807009144

25. American Diabetes Association (2016) Classification and diagnosis of diabetes. Section 2. In Standards of medical care in Diabetes2016. Diabetes Care 39(Suppl 1):S8-S16

26. Bingley PJ, Bonifacio E, Williams AJ, Genovese S, Bottazzo GF, Gale E (1997) Prediction of IDDM in the general population: strategies based on combinations of autoantibody markers. Diabetes 46(11):1701-1710. https://doi.org/10.2337/diab.46.11.1701

27. Bingley PJ (2010) Clinical applications of diabetes antibody testing. J Clin Endocrinol Metab 95(1):25-33. https://doi.org/10.1210/ jc. $2009-1365$

28. Craig ME, Jefferies C, Dabelea D, Balde N, Seth A, Donaghue KC (2014) Definition, epidemiology, and classification of diabetes in children and adolescents. Pediatr Diabetes 15(Suppl 20):4-17. https://doi.org/10.1111/pedi.12186

29. Fazeli Farsani S, van der Aa MP, van der Vorst MM, Knibbe CA, de Boer A (2013) Global trends in the incidence and prevalence of type 2 diabetes in children and adolescents: a systematic review and evaluation of methodological approaches. Diabetologia 56(7): 1471-1488. https://doi.org/10.1007/s00125-013-2915-z

30. Neu A, Feldhahn L, Ehehalt S et al (2018) No change in type 2 diabetes prevalence in children and adolescents over 10 years: update of a population-based survey in South Germany. Pediatr Diabetes 19(4):637-639. https://doi.org/10.1111/pedi.12622

31. Candler TP, Mahmoud O, Lynn RM, Majbar AA, Barrett TG, Shield JPH (2018) Continuing rise of type 2 diabetes incidence in children and young people in the UK. Diabet Med 35(6):737-744. https://doi.org/10.1111/dme.13609

32. Oester IM, Kloppenborg JT, Olsen BS, Johannesen J (2016) Type 2 diabetes mellitus in Danish children and adolescents in 2014. Pediatr Diabetes 17(5):368-373. https://doi.org/10.1111/pedi. 12291

33. O'Dea MI, O'Connell SM, O'Grady MJ (2017) Prevalence and characteristics of paediatric type 2 diabetes in the Republic of Ireland. Diabet Med 34(11):1603-1607. https://doi.org/10.1111/ dme. 13425

\section{Affiliations}

Christopher C. Patterson ${ }^{1} \cdot$ Valma Harjutsalo ${ }^{2} \cdot$ Joachim Rosenbauer $^{3} \cdot$ Andreas Neu $^{4}$ • Ondrej Cinek ${ }^{5}$. Torild Skrivarhaug $^{6}$ • Birgit Rami-Merhar ${ }^{7}$. Gyula Soltesz ${ }^{8} \cdot$ Jannet Svensson $^{9} \cdot$ Roger C. Parslow $^{10} \cdot$ Conxa Castell $^{11}$. Eugen J. Schoenle ${ }^{12} \cdot$ Polly J. Bingley ${ }^{13} \cdot$ Gisela Dahlquist $^{14}$. Przemysława K. Jarosz-Chobot ${ }^{15}$. Dalè Marčiulionytė ${ }^{16,17}$. Edna F. Roche ${ }^{18}$. Ulrike Rothe ${ }^{19}$. Natasa Bratina ${ }^{20} \cdot$ Constantin lonescu-Tirgoviste $^{21}$. Ilse Weets ${ }^{22}$. Mirjana Kocova ${ }^{23}$. Valentino Cherubini ${ }^{24}$ • Natasa Rojnic Putarek ${ }^{25}$. Carine E. deBeaufort ${ }^{26}$. Mira Samardzic ${ }^{27} \cdot$ Anders Green $^{28}$

1 Centre for Public Health and UKCRC Centre of Excellence for Public Health Northern Ireland, Queen's University Belfast, Grosvenor Road, Belfast BT12 6BJ, UK

2 Folkhälsan Institute of Genetics, Folkhälsan Research Center, Helsinki, Finland
3 German Diabetes Center, Institute of Biometrics and Epidemiology, Leibniz Center for Diabetes Research at Heinrich Heine University Düsseldorf, Düsseldorf, Germany

4 University Children's Hospital, Tübingen, Germany 
5 Department of Pediatrics, Second Faculty of Medicine, Charles University and University Hospital Motol, Prague, Czechia

6 Division of Adolescent and Paediatric Medicine, Institute of Clinical Medicine, University of Oslo, Oslo University Hospital, Oslo, Norway

7 Department of Pediatric and Adolescent Medicine, Medical University of Vienna, Vienna, Austria

8 Department of Paediatrics, Medical School, University of Pécs, Pécs, Hungary

9 Department of Paediatrics and Adolescent Medicine, Copenhagen University Hospital, Herlev and Gentofte, Denmark

10 Leeds Institute of Cardiovascular and Metabolic Medicine, University of Leeds, Leeds, UK

11 Department of Health, Government of Catalonia, Barcelona, Spain

12 Department of Endocrinology and Diabetology, University Children's Hospital, Zurich, Switzerland

13 Diabetes and Metabolism, Bristol Medical School, University of Bristol, Bristol, UK

14 Department of Clinical Sciences, Paediatrics, University of Umeå, Umeå, Sweden

15 Department of Children's Diabetology, Medical University of Silesia, Katowice, Poland

16 Institute of Endocrinology, Lithuanian University of Health Sciences, Kaunas, Lithuania

17 Institute of Microbiology and Virology, Lithuanian University of Health Sciences, Kaunas, Lithuania
18 Department of Paediatrics, Tallaght University Hospital, Trinity College Dublin, The University of Dublin, Dublin, Ireland

19 Health Sciences/Public Health, Faculty of Medicine Carl Gustav Carus, Technische Universität Dresden, Dresden, Germany

20 Diabetes and Metabolic Diseases, University Children's Hospital, Department of Endocrinology, Ljubljana, Slovenia

21 National Institute of Diabetes Nutrition and Metabolic Diseases, NC Paulescu, Bucharest, Romania

22 Diabetes Research Center and Laboratory of Clinical Biology, Brussels Free University-Vrije Universiteit Brussel, University Hospital Brussels-Universitair Ziekenhuis Brussel, Brussels, Belgium

23 Department of Endocrinology and Genetics, University Children's Hospital, Skopje, Republic of Macedonia

24 Division of Paediatric Diabetes, Azienda University Hospital, Ancona, Italy

25 Department of Pediatric Endocrinology and Diabetes, University Hospital Zagreb, Zagreb, Croatia

26 Department of Paediatric Diabetes and Endocrinology, University of Luxembourg, Luxembourg, Luxembourg

27 Department of Endocrinology, Institute for Sick Children, Podgorica, Montenegro

28 Odense Patient data Exploratory Network (OPEN), Odense University Hospital/Department of Clinical Research, University of Southern Denmark, Odense, Denmark 